\title{
USing VSM Method to InCREASE VALUE Creation in Manual Production System
}

\author{
DURANIK, T.; RUZBARSKY, J. \& STOPPER, M.
}

Abstract: Implementation of lean production process is a major foal in manufacturing and production companies. This aim increase value creation and profitability of company. In this paper there are outlined three value creation states of the manufacturing process, based on the method of Value Stream Mapping. Very important part of knowledge, how to create a price for the customer is knowledge of the value creation. For the current state we had identified processes which contain of any type of "waste". Then we had suggest and described an ideal state, showing only minimum waste processes and at last a future state that could lead us and give us answers how to increase value and production flow efficiency in manual production system, because of reducing production costs.

Key words: VSM method, lean management, manufacturing bottleneck
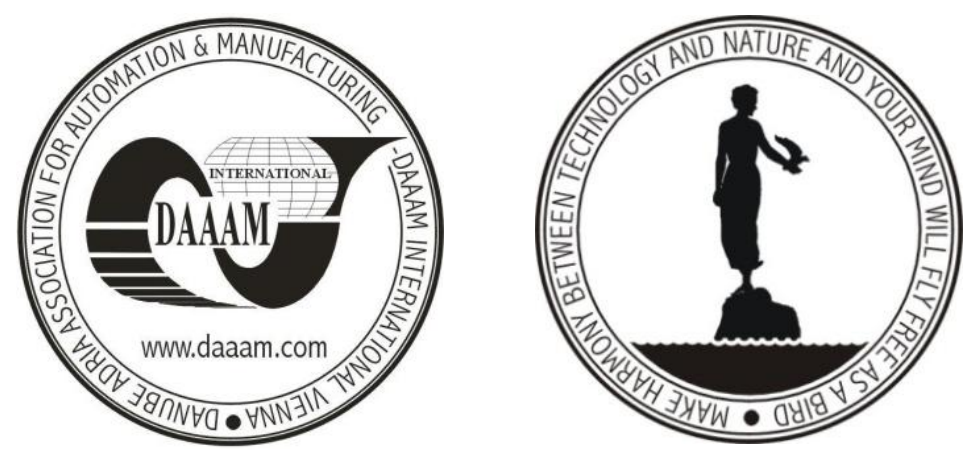

Authors' data: MSc. Duranik, T[omas]**; doc. MSc. PhD. Ruzbarsky, J[uraj]*; Prof. h.c. Dipl.-Ing. Dr. Sc. Stopper, M[arkus]**, *Technical University of Košice, Faculty of Manufacturing Technologies, Sturova 31, 080 01, Presov, Slovakia, **MKW® International, Industrial Research Center, Jutogasse 3, 4675, Weibern, Austria, tomas.duranik@mkw.sk, juraj.ruzbarsky@tuke.sk, markus.stopper@ieee.org

This Publication has to be referred as: Duranik, T[omas]; Ruzbarsky, J[uraj] \& Stopper, M[arkus] (2012). Using VSM Method to Increase Value Creation in Manual Production System, Chapter 47 in DAAAM International Scientific Book 2012, pp. 565-572, B. Katalinic (Ed.), Published by DAAAM International, ISBN 978-3901509-86-5, ISSN 1726-9687, Vienna, Austria

DOI: $10.2507 /$ daaam.scibook.2012.47 


\section{Introduction}

Nowadays, every company puts a lot of emphasis on product quality. The secret of success is no longer only to meet required quality criteria, but also to satisfy customer needs through providing a broad product range, short lead times and on fulfilling orders in right delivery times. In order to achieve these goals, it is necessary to optimize the manufacturing process by implementing a lean production process that intends to shorten time between suppliers and customers by eliminating waste in the production chain using the Value Stream Mapping method.

\section{Problem statement}

Assessing the actual situation, the company shows too many release failures and a waste production that is too high thereby exceeding delivery deadlines. As long as these problems are not solved, reserves are increasing in order to handle failure releases. Due to long delivery times the company might additionally face losses of revenue or business by missing critical customer deadlines or paying SLA penalties.

\section{Goal and application area}

Application of Value Stream Mapping helps to ensure that all manufactured products customers reach without any defects in compliance with delivery dates and without the production of any waste. This can be achieved by increasing efficiency, control and productivity in the production.

This case study shows the application of Value Stream Mapping on production processes in a medium sized manufacturing company.

\section{Value stream mapping (VSM)}

Value Stream Mapping is a tool commonly used in lean continuous improvement programs to help understand and improve the material and information flow within organizations. As with any lean management toolset the principle aim of Value Stream Mapping is to improve processes. (Murman et al, 2002) This is achieved by highlighting areas of waste generation within a process, thereby enabling businesses to eliminate these activities. Value Stream Mapping also has the benefit of categorizing process activity into two main areas: value add, non value add (but necessary)/waste.

1) A value adding process is any step in the production process that improves the product for the customer.

2) Non-Value Add (NVA)/Waste. Non-value adding is an activity that consumes time and/or resources and does not add value to the service or product for the customer. These activities should either be eliminated, simplified, reduced or integrated.

Hines and Rich defined the following "7 Wastes": Overproduction, Delay, Transporting, Over-Processing, Inventory, Motion and Making Defective Parts. 


\section{Applying value stream mapping}

In every organization products will follow in an exact stream or a similar path from beginning to end. In a first step all existing value streams have to be identified. Then a single specific value stream is chosen it is called the model line. It serves as a model for all the other value streams. After choosing a representative the value stream map can be drawn. The various steps of value stream mapping are shown in Fig. 1, Fig. 2 and Fig. 3.

\subsection{Current state map}

Critical point at the beginning of each improvement is the clear specification of the product value as it is delivered to the end customer. Example of a current state map is shown on Fig.1.

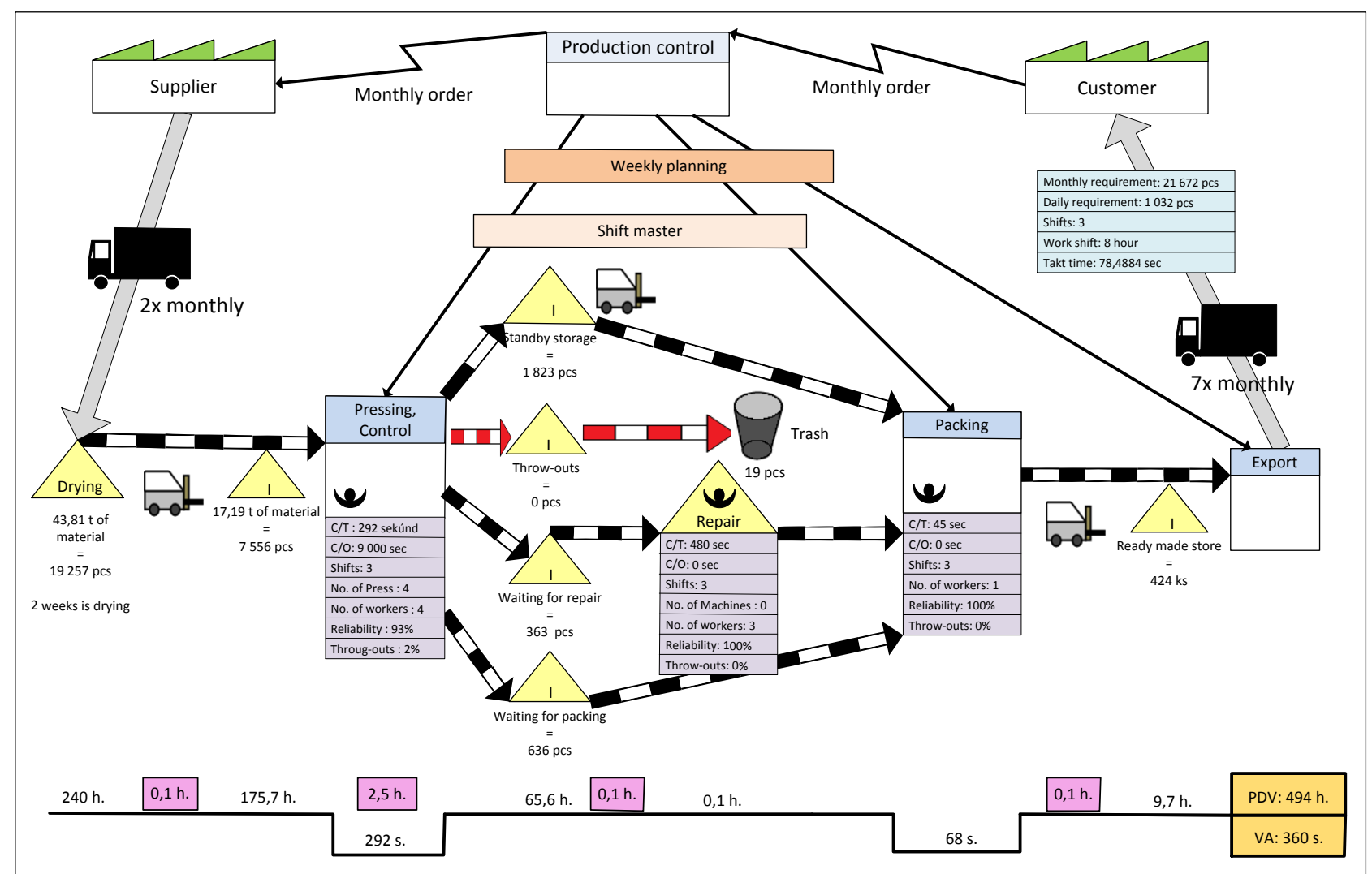

Fig. 1. Current state map of VSM

Therefore in order to map the customer different questions need to be answered (What is the monthly requirement?, How many pieces are produced in one day? etc.). Daily demand of the customer in this specific example is 1.032 pcs. Orders come in on a monthly basis and delivery to the customer is 7-times per month. Value adding comprises two processes: compression molding and packaging. Non value adding comprises a one process, which is repairing of the product. To each value or nonvalue adding processes, we put corresponding time on a time line under the VSM map. After counting it together, the lead time of current state is 494 hours which is 20,59 days and the value adding time is only $360 \mathrm{sec}$. Next important numbers wich we need are the tact time (1) and a value adding index (2). Under our conditions the 
production tact time of the order is 78,5 seconds, it means that every 78,5 second we need to produce one product for the customer order. The ratio of value adding index is a rate between lead time and value adding time. This index is expressed in percentage. For our situation it is $0,0202 \%$.

$$
\text { Takt time }=\frac{\text { shifts } *(L O W-B T)}{D O}=\frac{3 *(8 * 3600-1800)}{1032}=\frac{81000}{1032}=\underline{\underline{78,5 \mathrm{sec}}}
$$

LOW - length of work shift [in sec]

BT - break time [in sec]

DO - daily order [in pcs]

$$
V A i=\frac{\sum_{i=1}^{n} V A_{i}}{P D V} * 100 \%=\frac{360}{1778400} * 100 \%=\underline{\underline{0,0202 \%}}
$$

$\mathrm{VAi}$ - value adding index

VA - value adding time [in sec]

PDV - lead time [in sec]

\subsection{Ideal state map}

The ideal state map means, respectively describes, processes with minimum waste processes. Example of a ideal state map is shown on Fig.2.

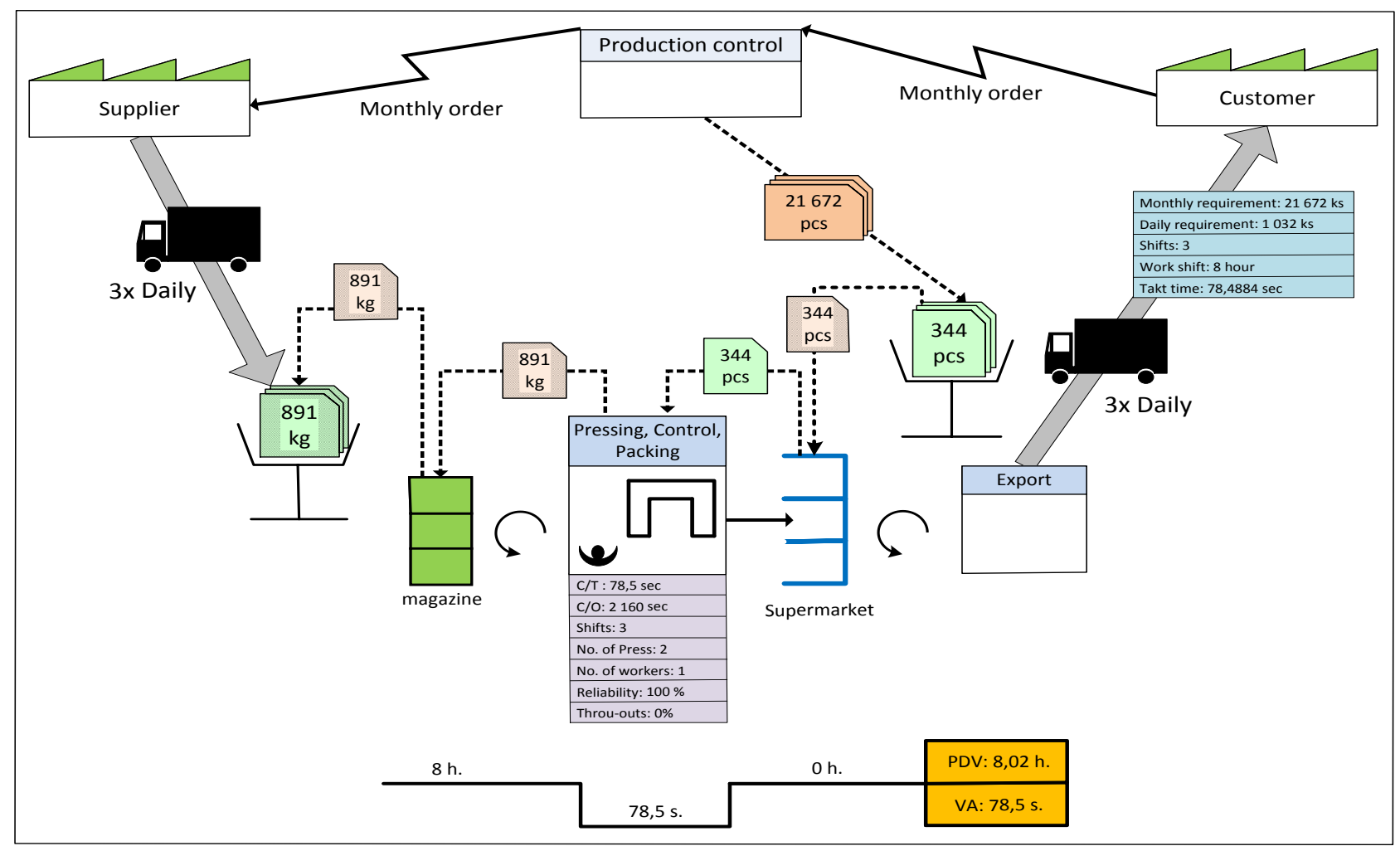

Fig. 2. Ideal state map of VSM 
In this context the word "ideal" means, that in the near future in production reality it may not be really feasible to reach this optimum state.

The ideal state does not take into account that the distance to the supplier might be far, that a daily supply with thermoset raw material cannot be granted as the material has to dry for two weeks in stock, that the production is also dependent on material quality and that the duration of compression molding itself cannot be influenced. In the ideal state map of VSM the lead time is 8,02 hours and the value adding time 78.5 seconds. The lead time has improved from 20,59 days to 8,02 hours and the ratio of value adding index is $0,2718 \%$, as compared to a ratio of $0,0189 \%$ in the current state, which is an improvement of more than 10-times. In the ideal state processes are changed, and they are in one U-cell. As a planning system, KANBAN is used as a pure pull production planning system.

\subsection{Potential improvements of current state map}

Removed weaknesses from current state will create the future state map Fig.4.

Potentials to improve individual types of waste:

1) Delivery of starting material - Introduction of weekly supply system - will consist of more frequent deliveries of thermosets, providing a reduction in inventory and thus less volume commitments corporate funds to stored material.

2) Material storage - Reduced non added value inventory and reduce material inventory - unnecessarily large amount of thermosets in material stock will be removed through a change cycle of supply.

3) The Pressing process with control - Reducing cycle time, the casting time, increase reliability, and reduce throw-outs and introduction of U-cell - each of these activities included in the pressing process should be removed or are put into the next phase of process improvement.

4) Supply waiting packaging - Introduction of pull and supermarket system Introduction of pull system before the packaging process will set the entire production cycle.

5) Dispatch of finished goods - Introduction weekly expedition - in this case, the finished product will commit financial resources as much as before and also minimizes storage space.

6) Repair process - reducing the number of operators - due to an improvement in the moulding process via better control

These potential improvements of current state map are shown on Fig. 3. 
Duranik, T.; Ruzbarsky, J. \& Stopper, M.: Using VSM Method to Increase Value Creation in Ma...

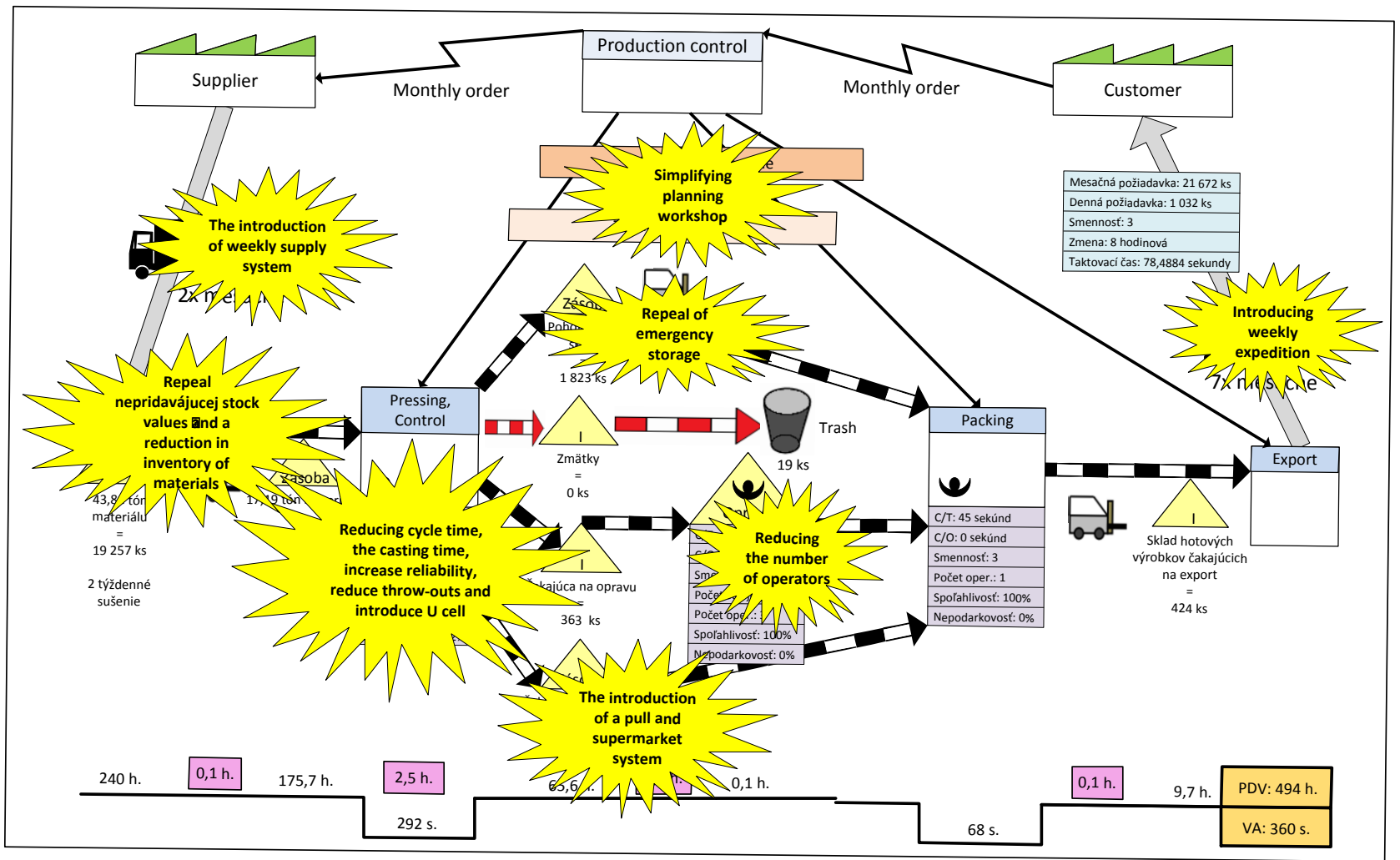

Fig. 3. Potential improvements of current state map

\subsection{Future state map}

Questions about supporting improvements, material flow, customer delivery strategy and information flow are answered in the future state map of VSM. Example of a future state map is shown on Fig. 4.

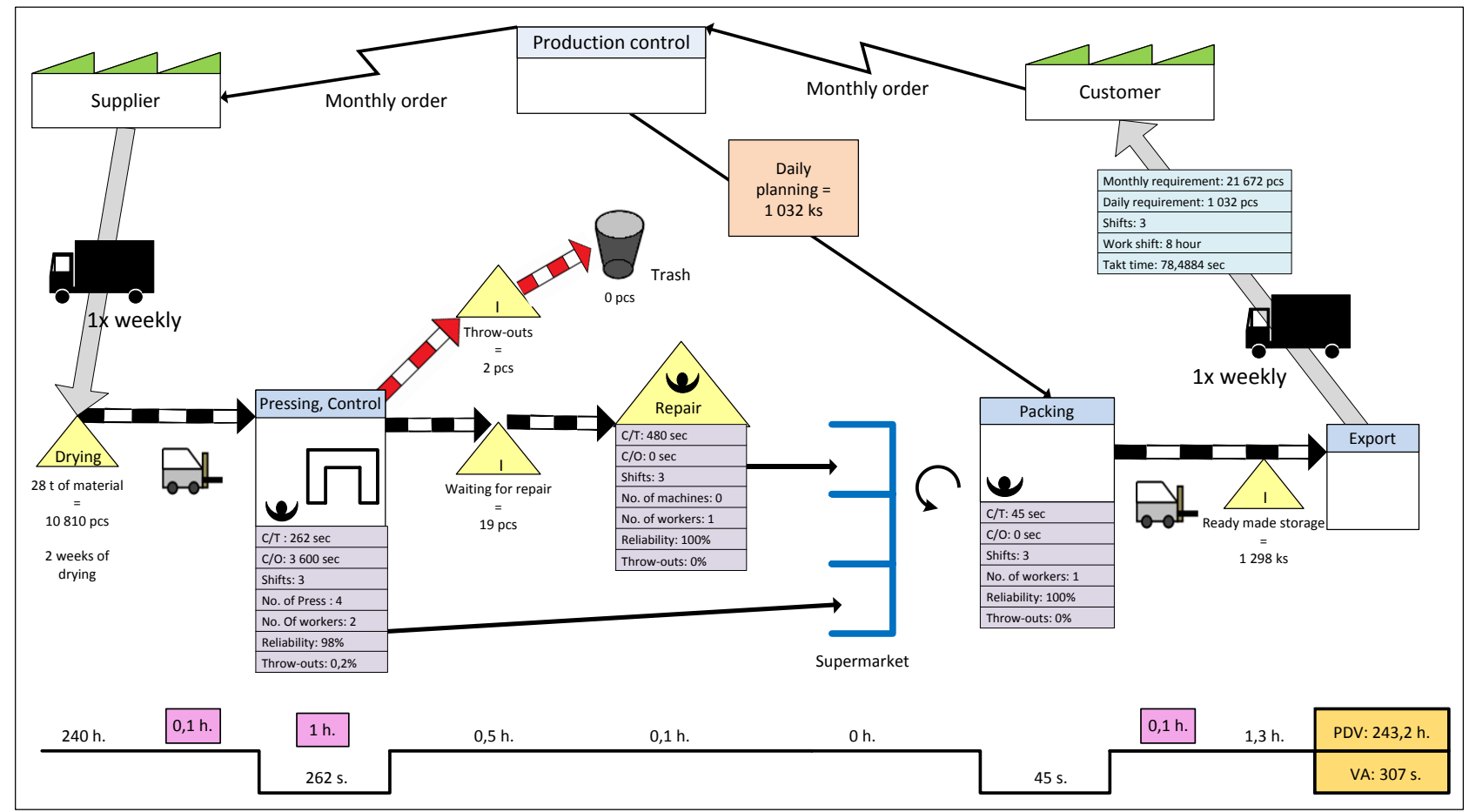

Fig. 4. Future state of VSM 
After developing the current state, into the future state, lead time is reduced from 68,84 days to 19 days using the kanban method of lean management for the synchronization of production and material flow. The ratio of continuous work time, to value adding time, indicated as the percentage of the total production time is $0,00838 \%$, which is an improvement of more than 1,5-times over the present state.

\subsection{Identification of bottleneck process}

The bottleneck process is an operation, with the longest cycle time over the registered overall takt time. In this example, the whole tact time is 78.5 seconds with the process of compression molding displaying the longest cycle time. The compression molding time cannot be reduced to 78.5 second because the technology itself would not allow such a reduction. With a compression time of 78.5 seconds on this parts which the company made, the quality would get so low, that it would not be sellable to the customer anymore.

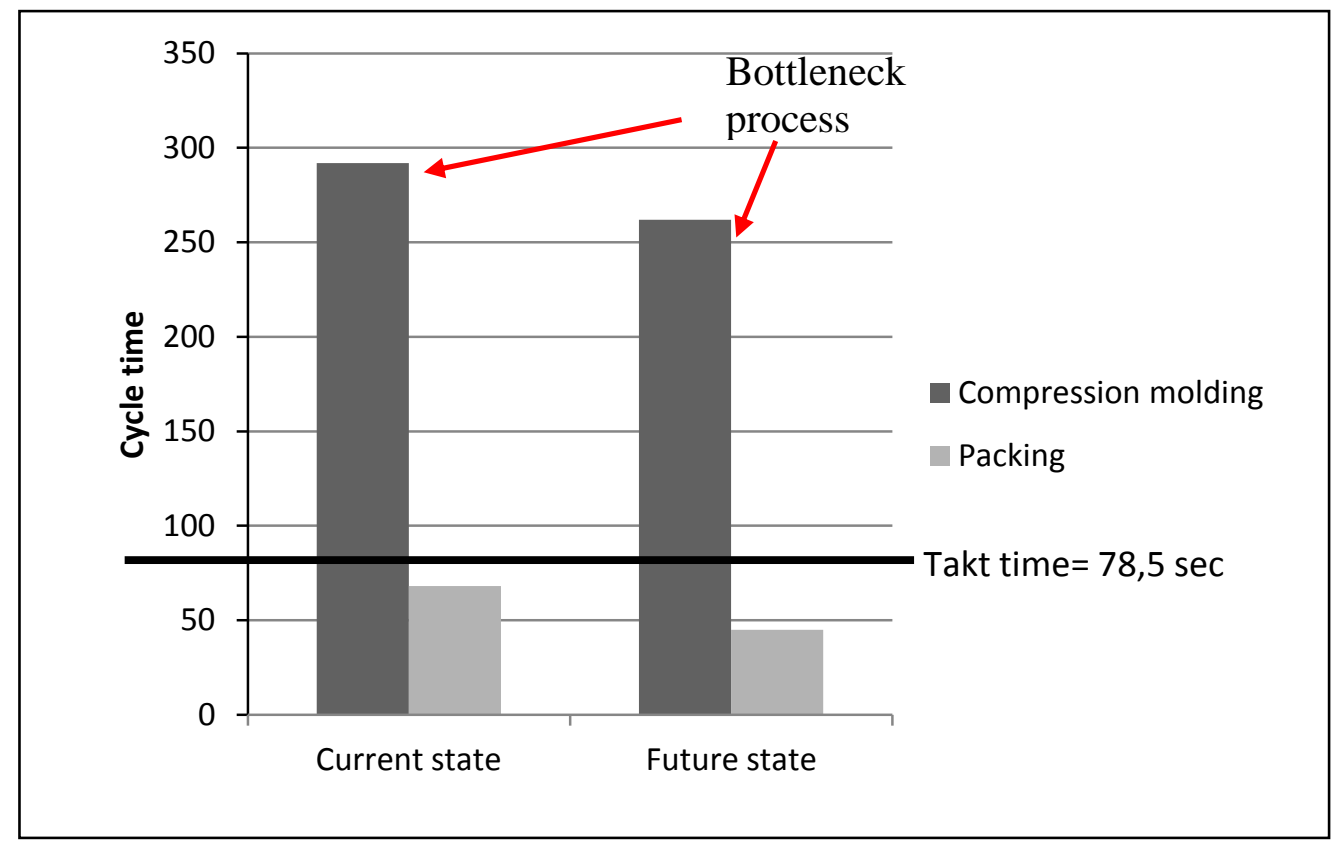

Fig. 5. Identifying the bottleneck process

\section{Conclusion}

In order to continuously improve lean production processes, future state scenarios should outline the target, that the current state scenario should strive to achieve. The Value Stream Mapping method has proven to be a highly useful tool, that helps not only to eliminate specific waste but also a value creation. By using the VSM method we were able to achieve the following results:

- Lead time reduction of $48 \%$

- Productivity increase of $28 \%$

- Inventory decrease of about $55 \%$

These results are not final results; they can be further improved with KAIZEN philosophy, with help of the future introduction of integrated automation and control systems (Pasko, J. and Gaspar, S. 2007). When the company strives to become a 
"lean manufacturer" in the future, values streams will be analyzed by applying VSM, thereby defining bottleneck processes and improving overall production efficiency.

Made initial proposals should also serve as a standard implementation of these projects to other departments. Savings and benefits described previously quantified only a small fraction of what the company expects from a continuous process improvement, not only in production.

\section{Communication}

Questions? Problems? Dilemmas? Related to the publishing of this paper. Please contact us from http://www.daaam.com or from "Scriptorium" over form "Corresponding author informs". Please don't use other channels (e-mail, fax, phone) for the communication related to the publishing of paper.

\section{References}

Arbulu, J. R. \& Tommelein, D. I. (2002) Value Stream Analysis of Construction Supply Chains: Case Study on Pipe Supports Used in Power Plants, On-line Proceedings of the 2002 Annual Conference of the International Group for Lean Construction, Gramado, Brazil, August 2002

Duranik, T.; Stopper, M. \& Ruzbarsky, J.: Applying Value Stream Mapping to Identify Hidden Reserves and Avoid Bottlenecks, Annals of DAAAM for 2011 \& Proceedings of the 22nd International DAAAM Symposium, ISBN 978-3901509-83-4, ISSN 1726-9679, pp 0969-0970, Editor B. Katalinic, Published by DAAAM International, Vienna, Austria 2011

Hines, P. and Rich, N. (1997). The seven value stream mapping tools, International Journal of Operations \& Production Management, Vol. 17, Issue: 1, pp.46 64, ISSN: 0144-3577

Ishiwata, J. (1991). Productivity through Process Analysis, Productivity Press, Portland, USA, 1991. ISBN 1-563-27-185-0

Murman, E. et al. (2002). Lean Enterprise Value: Insights from MIT's Lean Aerospace Initiative, Palgrave Macmillan, 2002. pp. 72, ISBN 9780333976975

Lu, D. J. \& Kyōkai, N. N. (1989). Kanban Just-in Time at Toyota: Management Begins at the Workplace, Productivity Press, Portland, USA, 1989. ISBN 0915299-48-8

Pasko, J. \& Gaspar, S. (2007). Theory of the welding process automation. In: European and international standards in technical documentation. ELBA, Presov, Slovakia, 2007 s. $148-151$

Manlig, F. \& Vavruška, J. (2006). Decission-making Supported by Computer Simulation. Production systems Today and Tomorrow, ISBN 80-7372-159-7, Published by TUL - KVS, Liberec, Czech Republic, December 2006

Vavruška, J. 2008. Problems in production planning and management on limited capacities of small and medium-size enterprises. 2nd International Academic Conference ICTKI 2008, ISBN 978-80-7044-969-1,Published by U.J.E.P., Ústí nad Labem, Czech Republic, 2008 